\title{
Changes in Assessment and Its Influence on Student Learning in Secondary Schools in Brunei Darussalam
}

\section{Perubahan Pentaksiran dan Pengaruhnya terhadap Pembelajaran Pelajar di Sekolah Menengah di Negara Brunei Darussalam}

\author{
Norwati Abu Bakar ${ }^{1 *}$, Roslan Untong ${ }^{1}$, Awang Karhan Jait ${ }^{1}$ \\ ${ }^{1}$ Fakulti Pendidikan, KUPU SB, BRUNEI \\ *Corresponding Author
}

DOI: https://doi.org/10.30880/jstard.2020.02.03.014

Received 30 September 2020; Accepted 30 November 2020; Available online 31 December 2020

\begin{abstract}
This study is a phenomenological study that uses a qualitative approach. Seven participants were selected in this study by objective sampling. Data were obtained in triangulation involving various methods of data collection, namely by using in-depth interview methods, non-participant direct classroom observations, and documentary evidence. Findings show that the influence of assessment on learning among them is the mastery of lesson materials, improving academic achievement, and student attitudes. Overall, the findings of the study show that assessment changes have a positive influence on student learning in Islamic Education. It is therefore hoped that the assessment introduced will strengthen its implementation at all levels of schooling.
\end{abstract}

Keywords: Changes in assessment, influence, SBAFL, student learning

\begin{abstract}
Abstrak: Kajian ini merupakan kajian fenomenologi yang menggunakan pendekatan kualitatif. Tujuh orang peserta telah dipilih dalam kajian ini secara persampelan bertujuan. Data diperoleh secara triangulasi yang melibat pelbagai kaedah pengumpulan data, iaitu dengan menggunakan kaedah temu bual secara mendalam, pemerhatian langsung di bilik darjah secara non-participant dan bukti dokumen. Dapatan menunjukkan bahawa pengaruh pentaksiran terhadap pembelajaran diantaranya ialah penguasaan bahan pelajaran, meningkatkan pencapaian akademik dan sikap pelajar. Secara keseluruhannya dapatan kajian menunjukkan bahawa perubahan pentaksiran memberi pengaruh yang positif terhadap pembelajaran pelajar dalam Pendidikan Islam. Oleh yang demikian adalah diharapkan supaya pentaksiran yang diperkenalkan ini diperkasakan pelaksanaannya dalam semua peringkat persekolahan.
\end{abstract}

Kata Kunci: Perubahan pentaksiran, pengaruh, SBAFL, pembelajaran pelajar

\section{Pengenalan}

Kementerian Pendidikan telah memperkenalkan sistem pendidikan negara pada tahun 2009 yang dikenali sebagai Sistem Pendidikan Negara Abad ke-21 (SPN21) bagi meningkatkan kecemerlangan bidang pendidikan di negara Brunei Darussalam. Tujuan SPN21 ini adalah untuk menyediakan pelajar dengan ilmu pengetahuan dan kemahiran. Di 
samping itu, membekalkan mereka dengan nilai murni/tambah dan sikap mulia/terpuji melalui Pendidikan Islam dan konsep Melayu Islam Beraja, bagi memenuhi keperluan dan tuntutan zaman yang berubah (Jabatan Perkembangan Kurikulum 2009).

Dalam usaha menghasilkan pendidikan berkualiti, juga pengajaran dan pembelajaran yang cemerlang, SPN21 telah membawa beberapa perubahan besar dalam pendidikan di negara Brunei Darussalam. Salah satu daripada agenda perubahan itu adalah dari segi kaedah pentaksiran, iaitu yang dikenali sebagai Pentaksiran Kendalian Sekolah untuk Pembelajaran (setelah ini disebut SBAfL). Perubahan ini bertujuan untuk meningkatkan pengajaran dan pembelajaran para guru, membantu guru-guru menyediakan maklumat untuk pelajar dan mengurangkan ujian dan peperiksaan berlebihan. Di samping itu, juga bertujuan untuk menyediakan pembelajaran yang luas kepada pelajar supaya mereka memperoleh kemahiran asas, pengetahuan dan kefahaman dengan sikap serta nilai yang tepat untuk memastikan perkembangan secara menyeluruh. Jadi, pentaksiran ini bertujuan untuk menyumbang kepada peningkatan pembelajaran pelajar. Justeru perlu disepadukan dalam pengajaran harian dan pembelajaran di dalam bilik darjah.

Melalui pentaksiran baharu ini, guru diharap akan dapat memperbaiki mutu pengajaran dan seterusnya dapat mereka bentuk gaya pengajaran yang mampu mendatangkan keseronokan kepada pelajarnya. Hal ini adalah kerana pendekatan dan gaya pengajaran guru mempunyai implikasi yang sangat besar kepada keberkesanan proses pengajaran dan pembelajaran. SPN21 telah membawa perubahan yang besar dalam sistem pendidikan negara umumnya dan mata pelajaran Ugama Islam khususnya. Peranan guru dalam SPN21 ini adalah mewujudkan kehendak baru dalam mengendalikan persekitaran pembelajaran yang lebih produktif. Oleh itu, kajian ini dijalankan untuk mengenal pasti pengaruh perubahan pentaksiran terhadap pembelajaran pelajar menurut perspektif guru-guru Pendidikan Islam.

\section{Sorotan Karya}

Pentaksiran ialah sebahagian besar daripada aktiviti proses pengajaran dan pembelajaran. Menurut Abu Bakar dan Bhasah (2008), pentaksiran mempengaruhi pengajaran dan pembelajaran dengan tiga cara: pertama, pentaksiran memperkemaskan objektif pengajaran. Dengan adanya pentaksiran guru akan lebih berhati-hati apabila menyediakan objektif untuk pembelajaran. Selain itu bagi pelajar-pelajar, objektif yang jelas akan dapat memberi panduan untuk menumpukan pembelajaran mereka; kedua pentaksiran dapat menolong guru dan pelajar menentukan perkara-perkara yang belum dan sudah berlaku; dan ketiga melalui pentaksiran, sesuatu kursus dan cara mengendali dapat diperbaiki. Ramai pendidik dan ahli teori pentaksiran percaya bahawa integrasi pentaksiran dan pengajaran boleh meningkatkan kecekapan. Mereka yakin bahawa prosedur pentaksiran adalah alat yang sangat penting dalam pendidikan yang boleh meningkatkan pengajaran dan pembelajaran (Dochy F.J.R. et al. 2012).

Menurut Azizi (2010) dan Earl (2005) terdapat tiga matlamat pentaksiran dalam pendidikan iaitu: pentaksiran untuk pembelajaran (assessment for learning), pentaksiran sebagai pembelajaran (assessment as learning) dan pentaksiran kepada pembelajaran (assessment of learning). Pentaksiran untuk pembelajaran merujuk kepada pentaksiran formatif (Stiggins 2005). Pentaksiran untuk pembelajaran adalah bertujuan untuk meningkatkan pembelajaran boleh menyumbang kepada pembelajaran pelajar. Ia adalah proses mencari dan menginterpretasikan bukti untuk digunakan oleh pelajar-pelajar dan guru-guru bagi menentukan di mana pelajar dalam pembelajaran mereka, ke mana harus mereka tuju dan bagaimana cara terbaik untuk mencapainya (Assessment Reform Group 2002).

Oleh itu, pentaksiran perlu diintegrasikan dalam proses pengajaran dan pembelajaran di bilik darjah. Bimbingan dan tunjuk ajar guru berdasarkan data dari pentaksiran adalah sangat signifikan dalam meningkatkan pembelajaran pelajar. Apabila sistem pentaksiran yang kukuh diintegrasikan dengan pengajaran dan pembelajaran, penggunaan sistem penilaian yang berbentuk berterusan, keberkesanan pengajaran boleh dilihat dan terdapat peningkatan pembelajaran yang sangat kukuh (Black \& William 1998; Spandel 2001 dan Songster \& Overall 2003).

Pelaksanaan pentaksiran formatif atau pentaksiran untuk pembelajaran merupakan satu strategi pengajaran untuk mengenal pasti kemajuan pelajar, mempercepat proses pembelajaran, pembaikan motivasi dan membantu pembelajaran pelajar (Mc Millan 2007 \& Perie et.al 2007). Penilaian formatif juga boleh mempengaruhi pelajar dari aspek motivasi harga diri dan keyakinan mereka (Black \& William 1998). Dapatan kajian mengesahkan bahawa penggunaan pentaksiran formatif menunjukkan bukan sahaja meningkatkan dalam pencapaian akademik tetapi juga peningkatan terhadap pelajar pencapaian rendah (Glasson 2009). Pentaksiran yang berkesan boleh merapatkan jurang pencapaian murid (Stiggins dan Chappius 2005).

Dalam konteks di negara Brunei Darussalam, usaha untuk meningkatkan dan memantapkan lagi kualiti pengajaran dan pembelajaran di sekolah-sekolah menengah, maka pihak Kementerian Pendidikan telah melakasanakan perubahan dalam kaedah pentaksiran dengan memperkenalkan 'Pentaksiran Kendalian Sekolah untuk Pembelajaran atau lebih dikenali dalam kalangan guru-guru "SBAfL" (School Based Assessment for Learning) sebagai tambahan kepada sistem pentaksiran yang sedia ada. SBAfL adalah gabungan antara Pentaksiran Kendalian Sekolah, "School Based Assessment" (SBA), yang telah diamalkan secara meluas di sekolah-sekolah sejak pengenalan SPN21, dan Pentaksiran untuk Pembelajaran, "Assessment for Learning" (AfL). SBAfL adalah termasuk dalam komponen pentaksiran kendalian sekolah (SBA). Pentaksiran untuk pembelajaran yang baru ini dianggap sebagai sebahagian daripada sistem pendidikan baru dalam ciri-ciri amalan pengajaran abad ke-21. 
Melalui perubahan pentaksiran pencapaian pelajar dalam menguasai pembelajaran tidak hanya dinilai melalui peperiksaan akhir tahun dan berpusat. Bahkan pentaksiran dilaksanakan secara berterusan semasa proses pengajaran dan pembelajaran. Perubahan yang berlaku adalah dari bergantung pada menghafal, ujian dan peperiksaan untuk mengukur kemajuan pelajar kepada satu sistem di mana pelajar sendiri adalah rakan kongsi aktif dalam pembelajaran dan proses pentaksiran memberi faedah daripada maklum balas yang berkualiti tinggi dan sokongan pembelajaran berterusan. Kaedah pentaksiran ini boleh membantu untuk mempercepatkan pengajaran dan pembelajaran yang cemerlang (Chappius \& Chappius, 2008).

Pelaksanaan SBAfL ini diharap akan dapat melahirkan pelajar dan masyarakat yang berkemahiran $\left(21^{\text {st }}\right.$ century skills), kreatif dan inovatif, berdikari, mempunyai pemikiran yang kritis, orientasi kepada tujuan dan dinamik. Oleh yang demikian guru pendidikan Islam perlu menggunakan pelbagai strategi seperti mendorong untuk membantu pelajar ke arah pencapaian yang terbaik. Hal ini juga dijelaskan oleh Dochy (2001), bahawa matlamat utama pendidikan akademik adalah untuk menjadikan pelajar yang mempunyai pengetahuan dalam domain tertentu. Bagi mencapai matlamat tersebut perlu kepada pembangunan persekitaran pembelajaran yang lebih kuat yang merangkumi kedua-dua pengajaran dan pentaksiran. Pentaksiran adalah sebahagian dari proses dan alat yang berkesan dalam bidang pengajaran dan pembelajaran di dalam bilik darjah.

Dengan pelaksanaan SBAfL, ia telah dijangka bahawa semua guru yang terlibat dengan idea pentaksiran untuk pembelajaran yang berterusan menyediakan persekitaran pembelajaran kondusif untuk pelajar belajar. Pentaksiran untuk pembelajaran sebagai bentuk pentaksiran formatif boleh dikatakan sebagai bahagian yang penting dalam proses pengajaran abad ke 21, apabila dimasukkan ke dalam amalan bilik darjah ia menyediakan maklumat yang diperlukan untuk menyesuaikan pengajaran dan pembelajaran semasa ianya berlaku. Namun peralihan daripada sistem pendidikan yang mementingkan peperiksaan kepada sistem pendidikan yang menggalakkan pentaksiran berterusan mungkin merupakan menjadi satu cabaran bagi kebanyakan guru-guru di Brunei termasuklah guru-guru Pendidikan Islam.

\section{Metodologi}

Pendekatan kualitatif digunakan dalam penyelidikan ini. Bogdan dan Biklen (1998) menyatakan bahawa pendekatan kualitatif boleh menghasilkan maklumat mendalam dan menyeluruh tentang fenomena yang dikaji serta memberikan data yang kaya, mantap dan sahih serta berupaya menjawab persoalan kajian. Pengkaji telah memilih reka bentuk fenomenologi bagi kaedah kualitatif ini kerana pengalaman guru adalah fenomena yang menggambarkan kefahaman yang diperoleh dalam kehidupan mereka, yang sukar untuk dilihat, diukur dan dikira (Byrne 2001). Pemilihan penyelidikan fenomenologi ini membantu pengkaji untuk meneroka pengaruh perubahan pentaksiran yang diperkenalkan terhadap pembelajaran pelajar menurut perspektif guru pendididikan Islam.

Temu bual secara mendalam dilakukan terhadap tujuh orang guru pendidikan Islam bagi mendapatkan maklumat yang dikehendaki. Melalui temu bual inilah pengalaman setiap peserta kajian akan diperoleh. Pemilihan peserta kajian dilakukan secara persampelan bertujuan (purposive sampling) digunakan dalam kajian ini dengan menentukan beberapa kriteria yang ditentukan oleh pengkaji (Merriam 1998). Dengan menggunakan kajian fenomenologi, penyelidik perlu memastikan setiap peserta kajian telah mengalami fenomena yang berkaitan dengan kajian (Moustakas 1994; Creswell 1998). Kajian ini hanya melibatkan guru-guru yang mengajar mata pelajaran pengetahuan Agama Islam di sekolah menengah kerajaan sahaja. Peserta yang terlibat dalam kajian ini seramai tujuh orang. Pemilihan terhadap guru tersebut berdasarkan pengetahuan mereka terhadap pentaksiran dalam SPN21 kerana mereka ini telah diberi pendedahan kepada sistem pentaksiran baharu ini melalui bengkel Program Perkembangan Profesional dalam SBAfL yang telah diberikan oleh kementerian pendidikan, yang diharapkan cukup untuk menyediakan data yang bermakna yang boleh dianalisis. Satu lagi keperluan penting peserta dalam kajian ini sedang mengajar sama ada Tahun Tujuh atau Tahun Lapan. Pemilihan ini adalah disebabkan pelaksanaan pentaksiran yang baru ini diberi penekanan kepada pelajarpelajar dalam peringkat ini.

\section{Dapatan Kajian dan Perbincangan}

Berdasarkan data dari temu bual, terdapat tiga tema utama yang dapat dikenal pasti dalam menjelaskan bagaimana sistem pentaksiran yang baru mempengaruhi pembelajaran pelajar pendidikan Islam. Tema-tema tersebut ialah; 1) Penguasaan bahan pelajaran, 2) Meningkatkan pencapaian akademik, 3) Sikap pelajar. Penjelasan mengenai tema-tema ini dapat dilihat huraiannya, seperti berikut;

\section{Tema 1: Penguasaan Bahan Pelajaran}

Berdasarkan hasil kajian, pelaksanaan pentaksiran yang baharu ini memberi pengaruh terhadap pembelajaran pelajar. Berdasarkan kajian lepas, hasil kajian mendapati kebanyakan amalan pentaksiran guru menggalakkan 'rote learning', lebih menumpukan kepada penggredan dan membuat perbandingan di antara pelajar daripada mengukur peningkatan dan perkembangan pelajar (Black et.al dalam Arends dan Kilcher 2010). Tetapi daripada hasil kajian menunjukkan dengan adanya aktiviti-aktiviti yang melibatkan pelajar secara aktif banyak membantu pelajar menguasai bahan pelajaran. Perkara ini selaras dengan kenyataan yang diberikan oleh Cikgu Rosinah, “...pelaksanaan SBAfL memang membantu terhadap penguasaan bahan pelajaran...” (Cikgu Rosinah, TB1: 401). Hal ini juga disokong oleh 
Cikgu Hartini dengan menyatakan, “...dengan adanya SBAfL, meningkatkan kefahaman penuntut...” (Cikgu Hartini, TB2: 113). Menurut Cikgu Hartini, jika kefahaman pelajar meningkat, ia menunjukkan pelajar dapat menguasai bahan pelajaran. Hal ini kerana menurut mereka dengan mengalami dan merasai sendiri proses pengajaran dan pembelajaran tersebut telah membantu pelajar memahami isi pelajaran dengan mudah dan lebih ingat akan isi pelajaran walaupun tidak secara drastik.

Penguasaan bahan pelajaran ini juga bukan hanya dalam kalangan pelajar pada tahap tinggi, malah pelajar lemah juga menunjukkan peningkatan dalam penguasaan bahan pelajaran. Berdasarkan pengalaman mengajar, Cikgu Kartika berpendapat pelaksanaan SBAfL juga mempengaruhi pelajar yang berada pada tahap rendah. Beliau menjelaskan sepanjang beliau mengajar pelajar yang lemah, iaitu sebelum SBAfL dilaksanakan, pelajar tidak dapat menjawab soalan latihan yang diberikan kepada mereka, “... student yang kelas hujung (lemah) kalau dulu membuat soalan saja, lapas atu nada (lepas itu tiada) jawapan... tapi ani Alhamdulillah, berisi sudah.. (ada jawapan)...”, (Cikgu Kartika, TB1: 152). Hal ini membuktikan bahawa strategi SBAfL sangat memberi pengaruh yang positif terhadap penguasaan bahan pelajaran dalam kalangan pelajar sebagaimana yang dinyatakan oleh Muijs dan Reynolds (2011) bahawa startegi yang ada dalam SBAfL seperti penggunaan penyoalan lisan boleh membantu guru untuk mengenal pasti setakat mana kefahaman pelajar, mengukuhkan pembelajaran, untuk menjelaskan isi-isi penting dan sebagai langkah pengajaran (AAIA 2002). Selain itu, jika bahan yang disampaikan kepada pelajar dapat difahami dengan baik dan asas kefahaman yang diterima dapat difikir, proses internalisasi akan berlaku dan ia akan dapat diterjemahkan oleh pelajar sebagai sumber amalan dalam kehidupan (Sidek Baba 2006).

\section{Tema 2: Meningkatkan Pencapaian Akademik}

Selain peningkatan terhadap penguasaan bahan pelajaran, pencapaian akademik pelajar juga menunjukkan peningkatan setelah SBAfL dilaksanakan. Perkara ini dinyatakan oleh Cikgu Rosinah melalui kenyataan beliau “...Pelaksanaan SBAfL mendorong pelajar untuk berusaha meningkatkan pencapaian akademik...” (Cikgu Rosinah, TB1: 399). Kenyataan ini disokong oleh Cikgu Hartini yang menyatakan "SBAfL membantu pelajar meningkatkan pencapaian akademik mereka" (Cikgu Hartini, TB1: 32).

Menurut peserta kajian, aktiviti-aktiviti yang berasaskan kepada SBAfL telah mendorong pelajar untuk berusaha meningkatkan pencapaian akademik mereka, “...maksudnya setiap aktiviti yang mereka lakukan atu (itu), membantu peningkatan pencapaian... maksudnya di sini perkembangan pelajar jua (juga)... maksudnya student lebih ingat bah melalui aktiviti atu (itu)..." (Cikgu Hartini, TB2: 17). Dalam hal ini Cikgu Hartini berpendapat setelah beliau menjalankan penilaian-penilaian berasaskan kepada SBAfL, beliau boleh melihat pencapaian pelajar sedikit sebanyak meningkat. Bagi beliau, peningkatan ini adalah disebabkan adanya aktiviti-aktiviti dijalankan di dalam kelas yang dapat mengembangkan dan mengukuhkan ingatan pelajar terhadap sesuatu topik yang dipelajari, Hal ini selari dengan kenyataan yang dikeluarkan oleh Jabatan Perkembang Kurikulum (2009) bahawa SBAfL menyediakan guru dan pelajar dengan maklumat kualitatif tentang bagaimana pelajar telah berkembang dalam mata pelajaran mereka. Pentaksiran ini akan dapat memberi maklumat kepada guru tentang keberkesanan pengajarannya dan bagi pihak pelajar pula, mereka akan mengetahui tahap kebolehan serta pencapaiannya. Sebagaimana kenyataan Stiggins (2002) bahawa penggunaan pentaksiran formatif dalam bilik darjah boleh memaksimumkan pencapaian pelajar. Pakar pendidikan juga menyatakan bahawa pentaksiran formatif atau pentaksiran untuk pembelajaran dan pentaksiran sebagai pembelajaran mempunyai hubungan yang positif untuk meningkatkan pencapaian pelajar (Stiggins et.al 2006; William 2005 \& Popham 2001).

Selain itu, peserta kajian menyatakan dengan adanya pendedahan terhadap ciri-ciri yang perlu dikuasai oleh pelajar membantu pelajar untuk mencapai objektif pembelajaran dan sekali gus dapat meningkatkan pencapaian akademik mereka, termasuklah bagi pelajar pencapaian rendah. Hasil kajian ini sejajar dengan hasil kajian Glasson (2009) yang mengesahkan bahawa penggunaan pentaksiran formatif menunjukkan bukan sahaja meningkatkan dalam pencapaian akademik malahan juga peningkatan terhadap pelajar pencapaian rendah. Melalui pelaksanaan pentaksiran formatif, maklumat pencapaian pelajar diperoleh bagi mengetahui sama ada wujud kelemahan-kelemahan pelajar dalam proses pengajaran dan pembelajaran (Azizi \& Mohd Isha 2008).

\section{Tema 3: Sikap Pelajar}

Pelaksanaan SBAfL juga mempengaruhi sikap pelajar dari segi keyakinan, kekreatifan dan rasa kebertanggungjawaban. Menurut peserta kajian, pelajar menunjukkan sikap yang positif terhadap pengajaran guru sejak SBAfL diimplementasikan. Hampir kesemua peserta kajian yang terlibat dalam kajian berpendapat pelaksanaan SBAfL memberi kesan terhadap sikap pelajar dari segi keyakinan mereka. Cikgu Siti menyatakan dengan adanya SBAfL, pelajar menjadi yakin dalam pembelajaran mereka, “...dengan adanya SBAfL membuat kanak-kanak (pelajar) tu yakin jadinya, inda (tidak) malu..." (Cikgu Siti, TB1: 63). Cikgu Siti menjelaskan mengenai kesan pelaksanaan SBAfL terhadap pelajar meningkatkan keyakinan dalam diri pelajar sewaktu sesi pengajaran dan pembelajaran dijalankan. Menurut cikgu Siti, pelajar tidak lagi berasa malu untuk melakukan aktiviti-aktiviti yang disediakan oleh guru. Kenyataan ini disokong oleh Cikgu Rosinah dengan menyatakan, “...meningkatkan minat dan keyakinan pelajar untuk terus belajar...” (Cikgu Rosinah, TB1: 413). Sementara itu, Cikgu Hartini menjelaskan mengenai keyakinan diri pelajar meningkat sejak SBAfL diimplementasikan adalah disebabkan aktiviti-aktiviti yang disediakan oleh guru, “...melalui 
aktiviti yang diberikan dalam SBAfL meningkatkan keyakinan mereka (pelajar) bercakap..." (Cikgu Hartini, TB1: 203).

Selain itu, Cikgu Salmah juga mengutarakan pendapat yang sama dengan Cikgu Hartini dengan menyatakan aktiviti-aktiviti yang disediakan oleh guru membantu meningkatkan keyakinan pelajar sekiranya aktiviti tersebut sering dipraktikkan di dalam bilik darjah, sebagai contoh aktiviti lakonan seperti dalam kenyataan berikut, “...kalau aktiviti yang dijalankan oleh guru dalam SBAfL, macam aktiviti lakonan, anak (pelajar) yang pemalu contohnya.. kalau selalu mempraktikkan lakonan, lama-lama ia akan jadi satu keyakinan dalam dirinya..." (Cikgu Salmah, TB3: 103). Cikgu Salmah menjelaskan jika guru sering melaksanakan aktiviti-aktiviti yang dapat merangsang pelajar untuk belajar dan aktif dalam pembelajaran mereka, lama kelamaan keyakinan pelajar tersebut semakin bertambah dan pelajar berani untuk mengutarakan pendapat-pendapat mereka.

Selain itu, melalui aktiviti-aktiviti yang dirancang oleh guru seperti membuat poster, peta minda dan aktiviti lain telah memberi ruang kepada pelajar untuk lebih kreatif. Perkara ini dinyatakan sendiri oleh peserta kajian, “...meningkatkan kreativiti durang (pelajar)..." (Cikgu Hartini, TB3: 21). Begitu juga dengan Cikgu Siti yang berpendapat melalui aktiviti poster, pelajar boleh mengetengahkan kreativiti mereka dalam memberikan bayangan atau gambaran tepat tentang suatu tajuk pelajaran tersebut, “...membuat poster.. ahh kreatif jadinya pelajar itu...” (Cikgu Siti, TB2: 73). Ternyata daripada aktiviti-aktiviti yang diperkenalkan dalam kursus SBAfL telah memberi ruang kepada pelajar untuk lebih kreatif dalam memberikan idea-idea dan seterusnya menghasilkan pembelajaran yang berkesan seperti yang diutarakan oleh Cikgu Kartika, “Alhamdulillah pasal durang (pelajar) bagi idea kreatif lah...” (Cikgu Kartika, TB1: 149).

Peserta kajian mengakui bahawa pelaksanaan kaedah pentaksiran yang baharu ini (SBAfL) bukan saja meningkatkan kreativiti dan keyakinan dalam diri pelajar, tetapi juga mendorong pelajar untuk lebih bertanggungjawab terhadap pembelajaran mereka sehingga menghasilkan pembelajaran yang berkesan. Menurut Cikgu Serinah, pelaksanaan SBAfL di dalam bilik darjah telah mendorong pelajar untuk lebih bertanggungjawab terhadap pembelajaran mereka. Berhubung perkara ini beliau menjelaskan dalam SBAfL, "pelajar diberi tanggungjawab untuk meneroka pembelajaran mereka sendiri" dengan cara mengarahkan pelajar untuk "mencari maklumat-maklumat terbaru dari sumber lain seperti penggunaan teknologi maklumat, kitab-kitab lain dan sebagainya" (Cikgu Serinah, TB1: 96).

Cikgu Hartini turut menyokong kenyataan ini dengan menyatakan, “...dorang (mereka) ada komitmen...” (Cikgu Hartini, TBI: 596). Dalam hal ini Cikgu Hartini menjelaskan sebelum SBAfL diimplementasikan, kebanyakan waktu pelajar semasa proses pengajaran dan pembelajaran berlangsung dihabiskan dengan mendengar penerangan guru sahaja, tetapi setelah adanya SBAfL, "pelajar didedahkan dengan pelbagai aktiviti yang mendorong pelajar untuk bertanggungjawab dalam menyiapkan aktiviti tersebut" (Cikgu Hartini, TB1: 676).

Selanjutnya, Cikgu Siti juga berpandangan yang sama tentang pelaksanaan SBAfL menjadikan pelajar lebih bertanggungjawab. Berhubung perkara ini, beliau menjelaskan "penglibatan pelajar yang aktif" dalam proses pengajaran dan pembelajaran "memaksa pelajar untuk lebih bersedia dengan maklumat-maklumat tambahan mengenai isi pelajaran yang disampaikan kerana mereka tahu apa yang dikehendaki oleh guru mereka dan mengetahui objektif yang perlu dicapai” (Cikgu Siti, TB1: 258).

Pelaksanaan pentaksiran untuk pembelajaran merupakan satu strategi pengajaran untuk mengenal pasti kemajuan pelajar, mempercepat proses pembelajaran, pembaikan motivasi dan membantu pembelajaran pelajar (Mc Millan 2007; Perie et.al 2007). Hasil kajian ini disokong oleh kajian Kirton et. al (2007) yang memberikan beberapa bukti bahawa penggunaan pentaksiran formatif ini menimbulkan rasa kebertanggungjawaban pelajar terhadap pembelajaran mereka, yang menyumbang kepada pencapaian motivasi, keyakinan dan kelas bertambah baik terutama bagi pelajar yang mempunyai pencapaian rendah.

\section{Kesimpulan}

Secara keseluruhannya, pelaksanaan kaedah pentaksiran yang baharu ini (SBAfL) ternyata memberi impak yang penting terhadap keberhasilan pembelajaran pelajar. Kesannya bukan sahaja dilihat dari segi peningkatan pencapaian akademik pelajar, malahan juga dari segi sikap pelajar dan penerimaan positif mereka terhadap pendidikan Islam. Seterusnya, dapatan kajian juga menyumbang kepada dapatan baru kepada teori pengaruh SBAfL terhadap pembelajaran. Pentaksiran formatif bukan hanya meningkatkan penguasaan dan meningkatan pencapaian pelajar sebagaimana yang dijelaskan Stiggins et.al (2006), William (2005) dan Popham (2001), tetapi hasil daripada dapatan menyumbang kepada penemuan baru, iaitu dari aspek sikap, iaitu yakin, kreatif dan bertanggungjawab.

Dalam kajian ini, pelaksanaan SBAfL yang hanya tertumpu kepada guru yang mengajar tahun 7 dan tahun 8 juga memberi implikasi kepada pembelajaran. Perkara ini menunjukkan bahawa tidak semua guru diberi peluang untuk memperoleh pengetahuan dan kemahiran dalam pelaksanaannya. Dalam masa yang sama, pelajar-pelajar yang lain juga tidak mendapat pengalaman dan pendedahan dalam amalan SBAfL ini. Pelajar yang tidak dilibatkan dalam pelaksanaan SBAfL lebih terbiasa dengan sistem pentaksiran yang mementingkan ujian dan peperiksaan. Hal ini akan menjadikan mereka pasif dan tidak kreatif sedangkan pentaksiran SBAfL yang bersifat formatif lebih menggalakkan penyertaan pelajar dalam proses pengajaran dan pembelajaran, menggalakkan pelajar berusaha, berfikir dan menjadi lebih kreatif. Oleh yang demikian pentaksiran perlu dilaksanakan secara berterusan dan disepadukan dalam proses pengajaran dan pembelajaran guru pendidikan Islam supaya dapat membantu pembelajaran pelajar selain dari meningkatkan 
pengajaran guru. Selain itu guru pendidikan Islam juga perlu menyediakan pelbagai aktiviti untuk digunakan dalam mentaksir tahap pembelajaran pelajar mengikut aras kebolehan pelajar. Melalui aktiviti pentaksiran yang pelbagai, boleh menyumbang kepada insan yang seimbang dari aspek jasmani, emosi, rohani, intelek dan sosial. Apabila pelajar didedahkan sistem pentaksiran seperti ini akan membantu mereka dalam mencapai pembelajaran yang berkualiti dan sekali gus meningkatkan prestasi mereka dalam segenap bidang dan kemahiran.

\section{Penghargaan}

Penulis ingin mengucapkan terima kasih kepada Fakulti Pendidikan, KUPU SB atas bantuan dan maklumat yang diberikan untuk memastikan kejayaan kajian ini.

\section{Rujukan}

[1] Abu Bakar Nordin dan Bhasah Abu Bakar. 2008. Pentaksiran dalam Pendidikan Sain Sosial. Tanjong Malim: Universiti Pendidikan Sultan Idris

[2] Arends R.I \& Kilcher.A. 2010. Teaching for Student Learning: Becoming an Accomplished Teahcer. New York: Routlege

[3] Assessment Reform Group. 2002. Assessment for learning: 10 principles. http://www.assessmentreformgroup.org.uk

[4] Association of Assessment Inspectors and Advisers (AAIA). 2002. Secondary assessment practice: Selfevaluation and development material. http://www.aaia.org.uk

[5] Azizi Ahmad \& Mohd Isha Awang. 2008. Pengukuran dan Penilaian Pendidikan. Kuala Lumpur: Dewan Bahasa dan Pustaka

[6] Azizi Ahmad. 2010. Pentaksiran Pembelajaran. Selangor Darul Ehsan: Dawama Sdn. Bhd

[7] Black, P. \& William, D. 1998. Assessment and classroom learning. Assessment in Education 5(1): 7 - 73

[8] Black, P. \& William, D. 1998a. Assessment and classroom learning. Assessment in Education: Principles, Policy \& Practice 5(1): $7-744$

[9] Black, P \& William, D. 1998b. Inside the Black Box: Rising Standards through Classroom Assessment. London: School of Education, King College

[10] Bogden, Q. C. \& Biklen, S. K. 2003. Qualitative Research for Education Introduction to Theories and Methods. USA: Pearson Education Group. Inc

[11] Bryne, M. M. 2001. Understanding life experiences through a phenomenological approach to research. AORN Journal 73(4): 830 - 832. Retrieved Pro Quest Education Journal database

[12] Chappius, S. \& Chappius, J. 2008. The best value in formative assessment. Educational Leadership 65(4): 14 $-18$

[13] Chappius, S. \& Chappius, J. 2008a. The best value in formative assessment. Educational Leadership 65(4): 14 19

[14] Creswell, J. W. 1998. Qualitative Research Design: Choosing Between Five Traditions. Thousand Oaks, C.A: Sage

[15] Dochy, F. J. R. 2001. A new assessment era: different needs, new challenges. Research Dialogue in Learning and Instruction

[16] Dochy, F. J. R., et.al. 2012. Integrating Assessment, Learning and Instruction: Assessment Domain - Specific and Domain - Transcending Prior Knowledge and Progress. Netherlands Center For Educational Technology and Expertise

[17] Earl, L. 2005. Thinking About Purpose in Classroom Assessment. Assessment for, as and of Learning. Australian Studies Association Manitoba Education, Citizenship and Youth 2006. Rethinking Classroom Assessment with Purpose in Mind. Assessment for Learning, Assessment as Learning and Assessment of Learning. Retrieved from www.edu.gov.mb.ca/ks4/assess/wncp/index.html

[18] Glasson, T. 2009. Improving Student Achievement: A practical guide to Assessment for Learning. Australia Curriculum Corporation

[19] Jabatan Perkembangan kurikulum. 2009. Sistem Pendidikan Negara Brunei Abad ke-21(SPN21). Bandar Seri Begawan: Kementerian Pendidikan

[20] Kirton, A., Hallams, Peffers, J., Robertson, P. \& Stobart, G. 2007. Revolution, evaluation or a trojan horse? Piloting assessment for learning in some Scottish primary schools. British Educational Research Journal, vol. 33(4): $605-627$

[21] McMillan, J. H. 2007. Classroom Assessment: Principles and Practice for Effective Standards Based Instruction. 4th edition. Pearson Education. Inc

[22] Merriam, S. B. 1998. Qualitative Research and Case Study Applications in Eeducation. San Francisco, CA: JoseyBass

[23] Moustakas, C. 1994. Phenomenological Research Methods. Thousand Oaks, California: Sage Publications

[24] Muijs, D. \& Reynolds, D. 2011. Effective Teaching, Evidence and Practice. London: Sage Publications Limited 
[25] Overall, L. \& Sangster, M. 2003. Primary Teacher's Handbook. London: Confinium

[26] Perie, M., Marion, S. \& Gong, B. 2007. The role of interim assessment in a Comprehensive Assessment System. http://www.achieve.org/files/TheRoleofInterimAssessment.pdf

[27] Popham, W. J. 2001. The Truth About Testing: An Educator's Call for Action. Alexanderia, Virgina: Association for Supervision and curriculum Development

[28] Sidek Baba. 2006. Pendidikan Rabbani: Mengenal Allah Melalui Dunia. Selangor: Karya Bestari. Sdn. Bhd.

[29] Stiggins, R. J. \& Chappuis, J. 2002. Using student involved classroom assessment to close achievement gaps. Theory into Practice 44(1): $11-18$

[30] Stiggins, R. \& Chappuis, J. 2005. Using student-involved classroom assessment to close achievement gap. Theory and Practice 44(1): $11-18$

[31] Stiggins, R. J. \& Chappuis, J. 2006. What a difference a word makes. Jurnal of Staff Development 27(1): $10-14$.

[32] Stiggins, R. J. 2005a. From formative assessment to assessment for learning. A path to success in standard-based schools. Phi Delta Kappa 87(4): 324 - 325

[33] Stiggins, R. J. 2005b. From formative assessment to assessment for learning: A path to success in standard-based school. Phi Delta Kappan 87(4): 324 - 328

[34] Spandel, V. 2001. Creative Writers: Through 6 Trait Writing Assessment and Instruction (3rd Ed). London: Addison Wesley Longman Inc

[35] William, D. 2005. Assessment for learning: Improving teaching quality and test scores. Muat turun http://www.dylanwilliam.net 